\title{
Endocrine and metabolic aspects of the COVID-19 pandemic
}

\author{
Mónica Marazuela $^{1}$ (D) $\cdot$ Andrea Giustina $^{2} \cdot$ Manuel Puig-Domingo $^{3}$ \\ Published online: 9 July 2020 \\ (C) Springer Science+Business Media, LLC, part of Springer Nature 2020
}

\begin{abstract}
COVID-19 infection has tremendously impacted our daily clinical practice as well as our social living organization. Virtually all organs and biological systems suffer from this new coronavirus infection, either because the virus targets directly specific tissues or because of indirect effects. Endocrine diseases are not an exception and some of endocrine organs are at risk of direct or indirect lesion by COVID-19. Although there is still no evidence of higher predisposition to contract the infection in patients with diabetes and/or obesity, the coexistence of these conditions contributes to a worse prognosis because both conditions confer an impaired immunologic system. Cytokines storm can be amplified by these two latter conditions thereby leading to multisystemic failure and death. Glycaemic control has been demonstrated to be crucial to avoiding long hospital stays, ICU requirement and also prevention of excessive mortality. Endocrine treatment modifications as a consequence of COVID-19 infection are required in a proactive manner, in order to avoid decompensation and eventual hospital admission. This is the case of diabetes and adrenal insufficiency in which prompt increase of insulin dosage and substitutive adrenal steroids through adoption of the sick day's rules should be warranted, as well as easy contact with the health care provider through telematic different modalities. New possible endocrinological targets of COVID-19 have been recently described and warrant a full study in the next future.
\end{abstract}

Keywords Covid-19 · Diabetes mellitus · Obesity · Malnourishment · Pituitary · Thyroid · Calcium • Vitamin D . Hypoadrenalism

$\begin{array}{ll}\text { Abbreviations } & \\ \text { ACE } & \text { Angiotensin-converting enzyme } \\ \text { ACTH } & \text { Adrenocorticotropic hormone } \\ \text { BMI } & \text { Body mass index } \\ \text { COVID-19 } & \text { Coronavirus disease 2019 } \\ \text { DPP4 } & \text { Human dipeptidyl peptidase } 4 \\ \text { H1N1 } & \text { Influenza A } \\ \text { ICUs } & \text { Intensive care units } \\ \text { MERS } & \text { Middle East respiratory syndrome }\end{array}$

Mónica Marazuela

monica.marazuela@salud.madrid.org

1 Department of Endocrinology, Hospital Universitario de la Princesa, Instituto de Investigación de la Princesa, Universidad Autónoma de Madrid, Madrid, Spain

2 Institute of Endocrine and Metabolic Sciences Vita Salute San Raffaele University; Division of Endocrinology IRCCS San Raffaele Hospital, Milan, Italy

3 Endocrinology and Nutrition Service, Department of Medicine, Germans Trias i Pujol Research Institute and Hospital, Universitat Autònoma de Barcelona, Badalona, Spain
SARS Severe acute respiratory syndrome

SARS-CoV- Severe acute respiratory syndrome

2 coronavirus 2

TMPRSS2 Transmembrane protease serine 2

\section{Introduction}

Coronavirus disease 2019 (COVID-19) or severe acute respiratory syndrome coronavirus 2 (SARS-CoV-2) outbreak requires that endocrinologists move forward, even more, to the first line of care of our patients, in collaboration with other physicians such as those in internal medicine and emergency units. This will preserve the health condition and prevent the adverse COVID-19-related outcomes in people affected by different endocrine diseases. People with diabetes in particular, are among those in high-risk categories for developing serious illness modality of COVID-19 infection if they get the virus, but other endocrine diseases such as obesity, malnutrition and adrenal insufficiency may also be strongly impacted by COVID-19 [1, 2] (Fig. 1). 


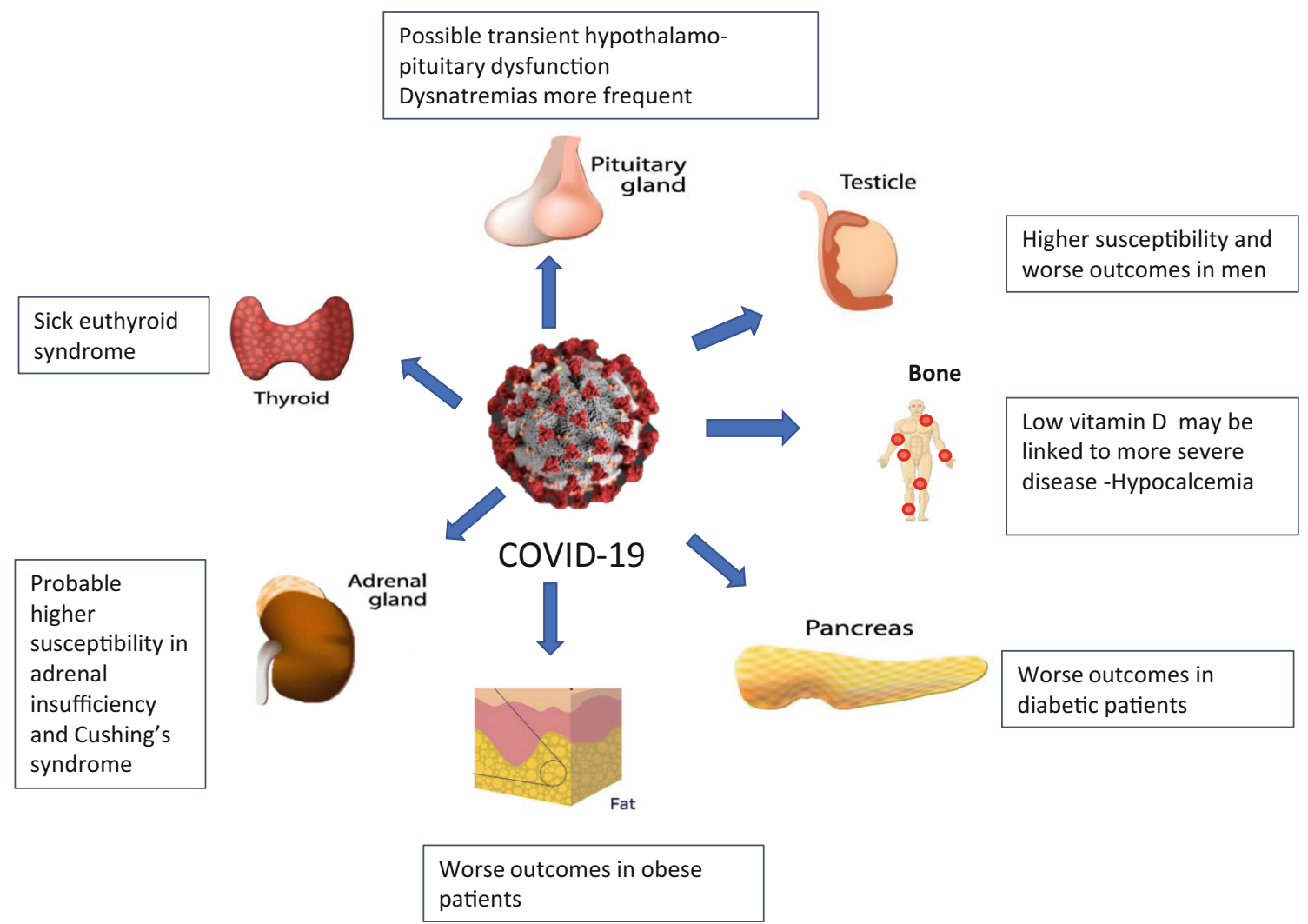

Fig. 1 Different endocrine glands/organs that can be affected by COVID19: 1) Pituitary: possible hypothalamic-pituitary disfunction and alterations in antidiuretic hormone metabolism. 2) Thyroid: sick euthyroid syndrome; 3) Adrenal: probable higher susceptibility to COVID-19 in adrenal insufficiency and Cushing's syndrome; 4) Bone. Low vitamin

\section{COVID-19 infection and diabetes mellitus}

Individuals with diabetes may be at increased risk of infections, especially influenza and pneumonia. This is why all people with diabetes are recommended pneumococcal and annual influenza vaccinations [3]. In general, it is assumed that this risk can be reduced, though not completely eliminated, through good glycemic control. Data about the incidence of COVID-19 in patients with diabetes are limited at present, but are increasing steadily every week; early reports have identified diabetes and obesity as predictors of higher incidence [4-7]. However, as population testing is still limited, and only in a few countries massive COVID-19 screening has been performed, whether or not diabetes is associated to a higher risk to contract COVID-19 is still unknown. The data currently available come mostly from hospital consultation cohorts (Fig. 2).

In this setting, the series by Petrilli et al. [8], in which 4103 patients were attended and 1999 were admitted to hospital, $15 \%$ of the overall cohort was found to have diabetes, which is not far from the prevalence of diabetes in the general population in their age range in the US. Thus, confirming what was found with Influenza A (H1N1) pandemic, Severe Acute Respiratory Syndrome coronavirus (SARS-CoV) and Middle East
D may be linked to more severe disease Increased risk of hypocalcemia. 5) Testicle: Higher susceptibility and worse outcomes have been reported in men; 6) Diabetes. Worse outcomes in diabetic patients; 7) Obesity. Worse prognosis in obese patients

Respiratory Syndrome coronavirus (MERS-CoV) outbreaks, the present coronavirus epidemics does not seem to account for a much higher capacity to infect people with diabetes [9].

\subsection{Increased risk of morbidity and mortality in patients with diabetes regarding COVID-19 infection}

Virtually all reports coincide that morbidity and mortality due to COVID-19 infection are increased by the presence of diabetes. In the series published by New York city hospitals, diabetes was more prevalent in those patients requiring admission (31.8\%) than in those not requiring admission (5.4\%) [8] (Fig. 2). Indeed, diabetes was also reported as an important risk factor for worse disease modality and excessive mortality while the occurrence of the Influenza A (H1N1) pandemic, SARS-CoV and MERSCoV outbreaks [4]. Influenza A (H1N1) pandemic, tripled the risk of hospitalization and quadrupled the risk of intensive care unit (ICU) admission when diabetes was present [3]. Consistent with that, data from China found that diabetes accounted for $8 \%-16 \%$ of hospitalized patients [10, 11], being diabetes prevalence across China around 5\% [12].

A large report of the Centers for Disease Control and Prevention of the United States showed that $78 \%$ of COVID- 
Fig. 2 Prevalence of diabetes mellitus in hospitalized COVID $19+$ versus general population in different countries The prevalence of diabetes is higher in hospitalized patients in USA and Spain, but not in China or Italy

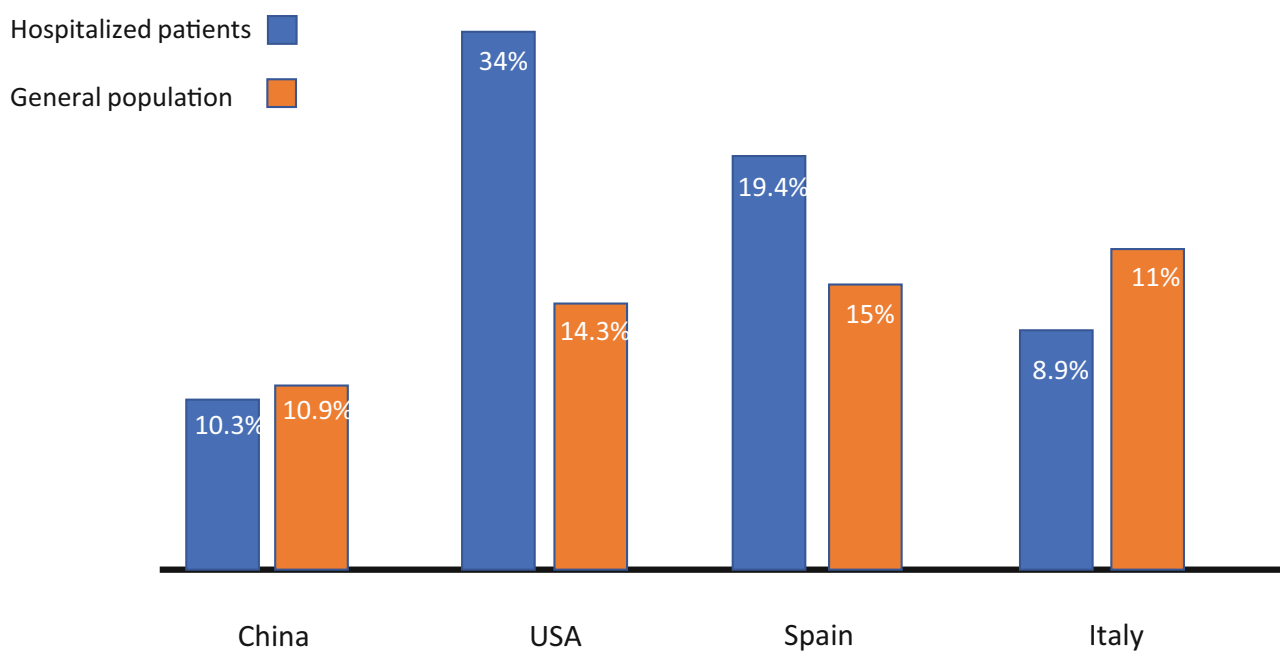

19 patients in ICUs had diabetes, cardiovascular diseases including hypertension or chronic lung disease [13]. A study performed by the Chinese Centre for Disease Control and Prevention including 72,314 cases (hospital admitted and ambulatory controlled) reported an overall mortality of $2.3 \%$ (1023 deaths among 44,672 confirmed cases) and in those having diabetes it reached $7.3 \%$ [1]. An additional report from China including 1590 hospitalized cases analyzed a composite endpoint including admission to ICU, intensive ventilation, or death, and after adjusting for smoking status and age. It was found that diabetes significantly increased the risk of severity according to the composite endpoint (hazard ratio $1.59,95 \% \mathrm{CI}$ 1.03-2.45); in this series, $34.6 \%$ of severe cases had diabetes compared to $14.3 \%$ in non-severe cases [14].

General mortality rates are difficult to evaluate due to the lack of data on non-symptomatic cases, as in most countries universal microbiological screening for COVID-19 has not been implemented, thus leading to an overestimation of the prevalence of case fatality. As indicated, in China the overall fatality rate was $2.3 \%$ and in people with diabetes it was $7.3 \%$ [1]. Data published in Italy, indicate that more than $70 \%$ of patients who died due to COVID-19 had either diabetes, cardiovascular disease or cancer as comorbidities [7].

In summary, according to current accumulated data, persons with diabetes are at increased risk for COVID-19 infection medical complications including death. Accordingly, an increased vigilance and testing of people with diabetes in specialized outpatient and general medicine clinics for COVID-19 is required, as well as a proactive hospitalization policy [15].

\subsection{Importance of glycemic control in those with coexistence of COVID-19 infection and diabetes}

To date, only a limited number of studies have addressed the role of hyperglycemia in the pathogenesis and prognosis of viral respiratory diseases $[1,16]$. However, it has been shown that elevated blood glucose levels can directly rise glucose concentrations in airway secretion [17]. In vitro glucose exposure of pulmonary epithelial cells significantly increases influenza virus infection and replication. In addition, elevated glucose levels impair the antiviral immune response. As a consequence, patients with diabetes use to have a higher viral charge as well as a much severe disease when infected with respiratory viruses. These findings are consistent with the reports of patients infected with the highly pathogenic avian influenza, in which hyperglycemia was associated with increased fatal outcome. Hyperglycemia may also affect pulmonary function, and therefore, respiratory dysfunction induced by influenza virus is exacerbated in patients with diabetes $[18$, 19]. In viral disease animal models, diabetes is associated with numerous lung structural changes, including augmented permeability of the alveolo-capillary membrane and a collapsed alveolar epithelium [20]. It is anticipated that glycemic control can have beneficial effects in patients with coexistent diabetes and viral respiratory diseases such as COVID-19. However, in the clinical setting, optimal metabolic control has been difficult to achieve mostly because of practical limitations encountered during the treatment of this patients' group [21]. Interleukin 6 and D-dimer levels are more elevated in hyperglycemic patients compared to normoglycemic ones. Both, patients with hyperglycemia not previously known as having diabetes and patients with known diabetes had a higher risk of severe disease than those without diabetes [22]. This emphasizes the importance of early detection of hyperglycemia at the hospital setting and the necessity of its prompt and effective treatment with insulin [23-25].

\subsection{Treatment for people with diabetes infected by COVID-19}

People with diabetes who are infected with COVID-19 may probably experience a deterioration of glycemic control, like 
in any other infectious episode. Proactive basal insulin dosage increase and correctional bolus may be required to maintain normoglycemia and prevent deterioration of metabolic control in those under insulin treatment [15].

Diabetic ketoacidosis coexisting with COVID-19 is particularly hazardous to treat, because of the risk of pulmonary fluid accumulation [26]. A report from a Chinese cohort consisting of 658 patients suggests that COVID-19 infection can cause ketosis per se in non-diabetic persons and may increase the risk of ketoacidosis in those with diabetes [27, 28].

In general, mild COVID-19 illness in people with type 2 diabetes on oral agents may be allowed to keep their usual treatment, provided that the patient stays under well control, but treatment modification must be indicated immediately upon clinical judgement, if development of severe COVID-19-related symptoms appear, especially high fever and potential dehydration. Oral agents, particularly metformin and sodium glucose cotransporter-2 inhibitors need to be stopped also, if serious illness condition develops [26]. Insulin is the preferred agent to control hyperglycemia in hospitalized patients, as it the most efficacious for any intercurrent situation, including infections [4]. Although sodium glucose cotransporter-2 inhibitors may predispose to ketoacidosis, a controversial clinical trial with dapaglifozin has been approved in COVID-19 patients with moderate illness including respiratory failure, the DARE-19 study (NCT04350593), aiming to evaluate the reduction of disease progression and death.

\subsection{Role of DPP-4 in COVID-19 as virus target}

Remarkably, human dipeptidyl peptidase 4 (DPP-4) has also been identified as a functional receptor of the Sprotein of MERS-Co-V [29]. MERS-CoV binds to the DPP-4 receptor-binding domain and interacts with $\mathrm{T}$ cells and nuclear factors, such as nuclear factor kappa $b$ (NF$\mathrm{kB}$ ), a key factor in the pathogenesis of inflammatory disorders. DPP-4 plays an important role in the regulation of the immune system by activating $\mathrm{T}$ cell repertoire and upregulating nuclear factor kappa b pathway [30]. Transgenic mouse models expressing human DPP-4 exposed to MERS-CoV had impaired inflammatory monocyte/macrophage phenotype, CD4+ T cells and lower expression of tumor necrosis factor alpha, interleukin 6 and Arg1 [31]. Remarkably, it has been recently demonstrated that human DPP-4/CD26 may interact with the S1 domain of the viral spike glycoprotein of SARS-CoV-2, thus allowing an additional way for the virus to enter the cell, beside the main one, which is angiotensin-converting enzyme (ACE)2 [32].

Thus, the question is whether DPP-4 inhibitors used currently for treatment of type 2 diabetes play a role not just regarding metabolic control, but also contributing to modify COVID-19 attack in these patients, either inducing protection or progression of infection (Fig. 3). It is tempting to postulate that inhibition of DDP-4 with the current antidiabetic drugs such as sitagliptin, vildagliptin or linagliptin may impair the virus/DPP-4 interaction, thereby protecting the cell from virus entrance. However, the binding of SARS-CoV-2 and MERS$\mathrm{CoV}$ takes place at residues not located nearby the DPP-4i binding pocket of current gliptin drugs, thus requiring more studies in order to clarify this question [33].

It is known that DDP-4 inhibition modulates inflammation and has anti-fibrotic effects; depending on the potency of these properties, DPP-4 inhibitors may eventually have some protective effects in case of severe COVID-19 infection. The potential decrease of the magnitude COVID-19 cytokines storm under DPP-4 inhibitors action sounds attractive but, so far, no data are available to provide a consistent answer.

\section{COVID-19 and obesity}

\subsection{Increased risk of morbidity and mortality in patients with obesity regarding COVID-19 infection}

Until recently, there were no specific data in the literature reporting that subjects with obesity have a higher risk of developing severe forms of COVID-19, as first studies from China [1] and Italy [34] did not provide data on body weight and height. However, last reports have found a strong link between obesity and admission to critical care as well as the use of invasive mechanical ventilation [35]. In a study from Shenzhen (China), obesity was associated with a $142 \%$ higher risk of developing severe pneumonia [36]. The Intensive Care National Audit \& Research Centre in United Kingdom observed that $72.1 \%$ of patients with confirmed COVID-19 were overweight or obese and that among patients with body mass index (BMI) $>30$ who had undergone intensive care, $60.9 \%$ of them died [37]. Among 4103 patients in New York City, BMI $>40 \mathrm{~kg} / \mathrm{m} 2$ was the second strongest independent predictor of hospitalization, after old age [8]. In a retrospective single French center evaluating 124 consecutive patients, obesity (BMI $>30 \mathrm{~kg} / \mathrm{m} 2$ ) and severe obesity (BMI $>35 \mathrm{~kg} / \mathrm{m} 2$ ) were present in $47.6 \%$ and $28.2 \%$ of cases admitted to intensive care unit. The need for invasive mechanical ventilation was associated with a BMI $\geq 35 \mathrm{~kg} / \mathrm{m} 2$ [38]. Several reports from around the world have previously identified obesity and severe obesity as risk factors for hospitalization and mechanical ventilation in the H1N1 influenza virus [39]. Together, these data raise the question of whether there is a mechanistic link between obesity and COVID-19 and whether obesity might independently contribute to COVID-19 risk or at least to more severe forms of the disease. 
Fig. 3 Possible endocrine and metabolic targets that have been considered for COVID-19 therapy. Different hormones and drugs have been included as possible targets for COVI-19 including melatonin, oxytocin, DPP-4 (human dipeptidyl peptidase 4), ACE-2 (angiotensin converting enzyme-2), estrogens and statins
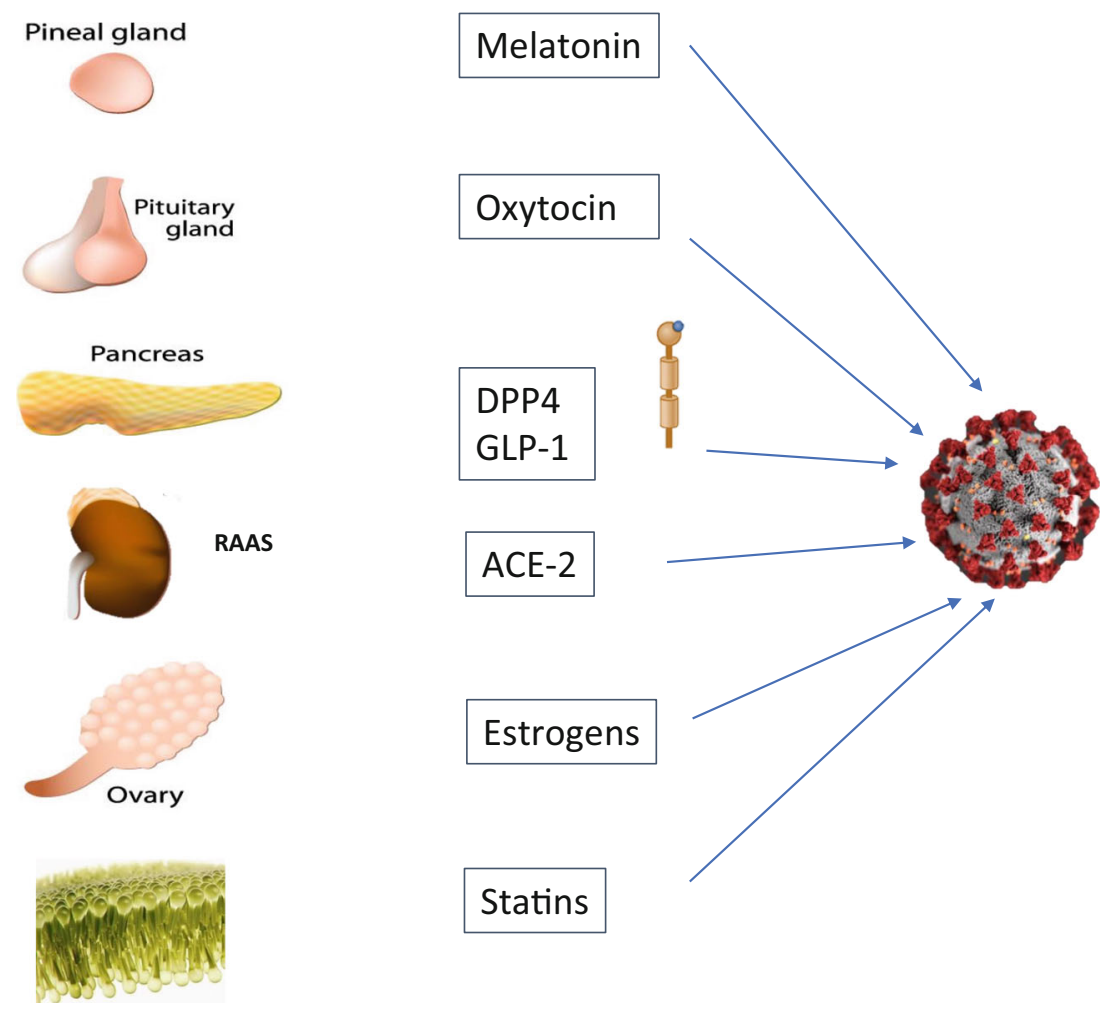

\subsection{How can obesity impact COVID-19 infection?}

The high impact of H1N1 Influenza and now COVID-19 in patients with obesity and severe obesity is probably related to the deleterious effects of obesity on pulmonary function (Fig. 4). Obesity is associated with decreased expiratory reserve volume, functional capacity and respiratory system compliance. Severe obesity causes sleep apnea syndrome and in those with increased abdominal obesity, pulmonary function is further impaired by decreased diaphragmatic excursion.

In addition, obesity contributes to increase the risk of different comorbidities including diabetes, cardiovascular risk and thrombosis, which may have a great impact in COVID19 infected patients outcomes, thus confirming that obesity rises the severity of COVID-19 infection [10, 40].

In addition, obesity could increase per se, the risk of different comorbidities including diabetes, cardiovascular risk and thrombosis in COVID-19, which can intensify the severity of COVID infection.

When it comes to the immune response, there is a clear association between obesity and chronic inflammation that can modify innate and adaptive immune responses, making the immune system more vulnerable to infections [41]. Obesity is related to low-grade inflammation that is associated to adipocyte hypoxia and dysfunction. This results in an exuberant secretion of pro-inflammatory cytokines such as tumor necrosis factor $\alpha$ (TNF- $\alpha$ ), interleukin (IL) $1 \beta$ and interleukin 6 and adipokines that lead to the recruitment of immune cells macrophage, $\mathrm{T}$ cell and B-cells, creating an auto-regenerating inflammation loop [42]. In this scenario, inflammatory macrophage and innate lymphoid subsets replace tissue regulatory M2 phenotypic cells. In addition, there are alterations of lymphocyte phenotype with a decrease in T regulatory and $\mathrm{Th} 2$ cells and an increase in Th1 an Th17. Viral infection may amplify the already primed organ cytokine response in adipose tissue [42]. In parallel, one of the most important mechanisms underlying the severity of lung disease in COVID-19 is represented by the so called "cytokine storm", which can lead to acute respiratory distress syndrome or even multiple organ failure in the worst case. The cytokine storm identified in multiple respiratory viral infections including COVID-19 exhibits an overproduction of interferon, tumor necrosis factor $\alpha$, interleukins, and different chemokines. Thus, considering that subjects with obesity have also a pre-set proinflammatory milieu, it is expected that COVID-19 could further exacerbate inflammation exposing them to higher levels of circulating inflammatory molecules compared to lean human subjects. This seems a feasible mechanistic explanation of the increased risk of severe complications of COVID-19 in subjects with obesity [43].

Obese individuals may exhibit greater viral shedding suggesting potential for enhanced viral exposure, especially if several family members are overweight. This may be aggravated in overcrowded multigenerational households, which are more common in the socioeconomically deprived communities in which obesity is prevalent [44]. In addition, in influenza infection obesity not only increases the severity but also enhances viral diversity. The altered microenvironment associated with obesity supports the emergence of more virulent 


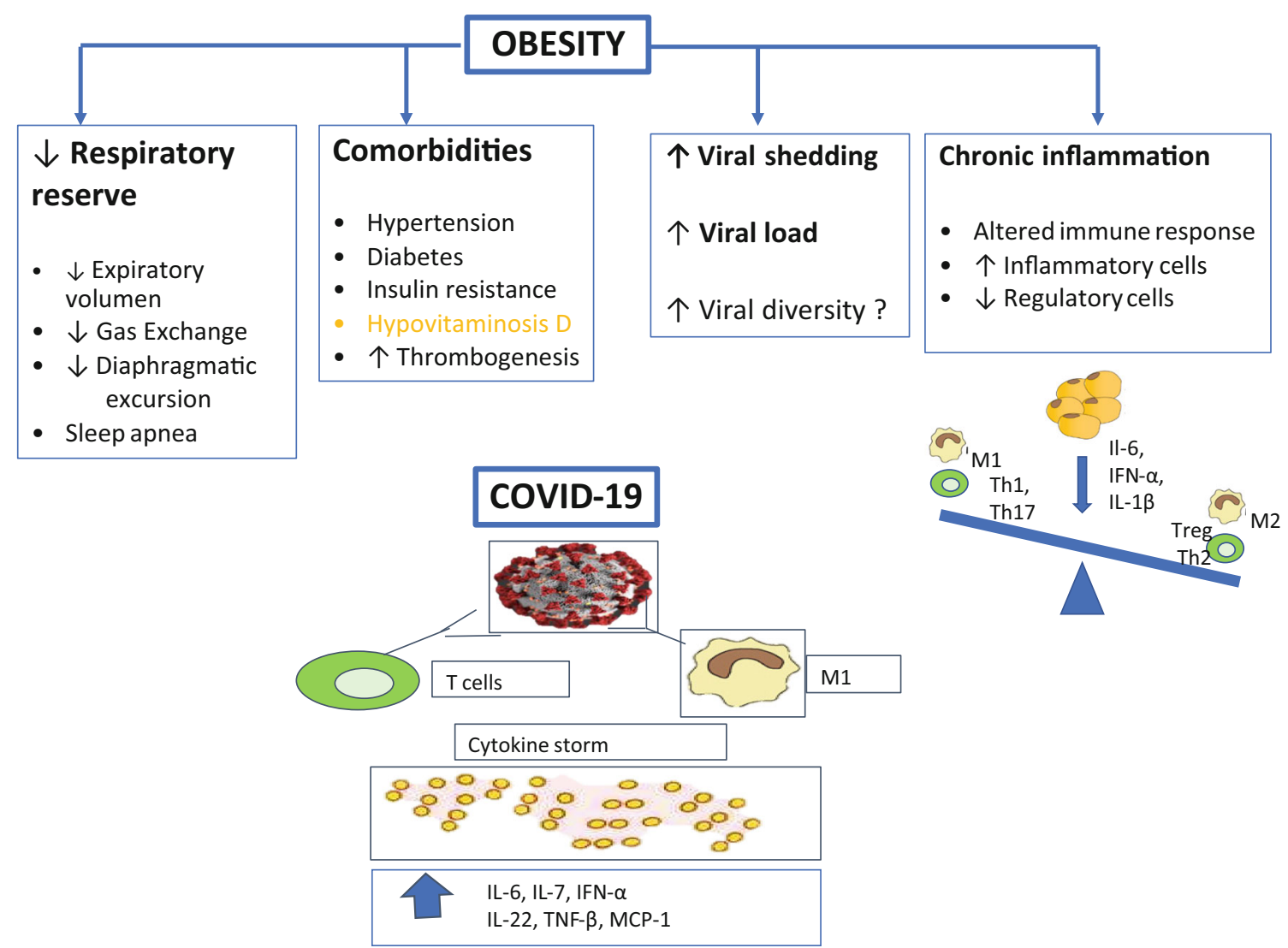

Fig. 4 Potential mechanisms that link obesity to worse outcomes in COVID-19. Obese patients have 1) a impaired respiratory function; 2) associated cardiovascular, metabolic and thrombotic comorbidities which reduce the capability to cope with COVID-19. In addition, obese patients have 3 ) increased viral shedding and viral load and 4) an amplified

influenza virus population capable of inducing greater disease severity. This could be related to an impaired interferon response, which is seen in experimental models, both in obese mice and obesity-derived human bronchial epithelial cells [45]. The same could happen in COVID-19 infection.

Finally, subjects with obesity have also mechanical issues related to excessive weight that make difficult an early diagnosis with pulmonary ultrasound and other imaging techniques, thus leading to a diagnosis of COVID-19 in the advanced stage which is most associated to highest mortality. The lack of medical or intensive care units not designed to accommodate optimally patients with severe obesity, the difficulty of intubation and insertion of catheters related to excess of weight may lead to a slowdown in therapeutic steps, worsening prognosis in patients with obesity and COVID-19 [46].

\subsection{Recommendations for people with obesity regarding COVID-19 infection}

There is a need for increased vigilance, priority on detection and testing, as well as a proactive therapy policy for patients with obesity and COVID-19 infections. The assessment of immune response due to altered balance between inflammatory and regulatory cells. During COVID-19 infection there is also an altered immune response that is amplified by the dysregulated immune system of the obese patients

metabolic phenotype is crucial. This includes body mass index, waist and hip circumferences and levels of glucose. Such measurements might not be forgotten to be done, both, in the primary care setting as well as in the hospital setting to accurately assess the risk of these persons.

It is critical that patients with body mass index greater than 40 , which has been reported as a critical cut-off for mortality risk [8], take all the possible precautions to avoid infection. Losing weight, lowering blood pressure and controlling blood sugar have always been important to prevent severe health consequences, but the risk of severe COVID-19 infection might now be another important reason to focus on these issues.

Persons with obesity who become COVID-19 ill and require treatment in intensive care units present very important challenges in their therapeutic management, as it is more difficult to intubate them. It can also be more difficult to obtain diagnostic imaging (as there are weight limits on imaging machines) and patients are more difficult to position and transport by nursing staff. Also, the decision to extubate those patients is more challenging when it comes to these patients. Healthcare systems in general are not yet well set up enough to manage an increasing number of patients with obesity in ICUs 
and the current crisis could probably highlight their limitations even more.

\section{Nutrition \& vitamin D and COVID-19}

Regarding undernourished subjects, COVID-19 infection is associated to a high risk of malnutrition development, mostly related to augmenting requirements and the presence of a severe acute inflammatory status. These patients show also a hyporexic state, thus contributing to an acute negative nutritional balance. Estimated nutritional requirements for these patients are $25-30 \mathrm{kcal} / \mathrm{kg}$ of weight and $1.5 \mathrm{~g}$ protein $/ \mathrm{kg} /$ day [47]. A nutrient dense diet is recommended in hospitalized cases including high protein supplements, administered in 2-3 intakes per day and containing at least $18 \mathrm{~g}$ of protein per intake. If nutritional requirements are not met during hospital stay, complementary or complete enteral feeding may be required and, in case that enteral feeding may not be possible due to inadequate gastrointestinal tolerance, the patient should be put on parenteral nutrition. COVID-19 patients' outcome is expected to improve with an adequate nutritional support.

Vitamin D deficiency is widespread in Southern Europe where vitamin D fortified food is not widely used [48]. Vitamin D insufficiency has been reported to increase predisposition to systemic infections and to impair immune response or even to enhance the development of autoimmune diseases [49]. Moreover, it has been shown that vitamin D supplementation can prevent respiratory infections [50] and poor vitamin D status may aggravate the health outcome of ICU patients while its correction could decrease morbidity and mortality in this clinical setting [51]. Therefore, besides the hypothesis that hypovitaminosis D may be a predisposing factor to COVID19 infection and aggressiveness in some European countries [52], we strongly recommend to maintain vitamin D treatment in those already diagnosed with hypovitaminosis D [53] and suggest considering the supplementation with vitamin D of elderly comorbid persons at home confinement if they are no yet under supplementation $[54,55]$. Studies on levels of $25 \mathrm{OH}$ Vitamin D and their prognostic role in COVID-19 as well as on potential benefits of vitamin $\mathrm{D}$ intervention in this clinical setting are underway [56].

\section{Lipids and COVID-19}

Hypertrygliceridemia has been described as a side effect during COVID-19 infection, with four cases reported up to date. In two of them hypertrygliceridemia was related with lopinavir/ritonavir treatment [57] and in two others, patients were receiving a combination of this therapy with tocilizumab [58]. Lopinavir/ritonavir has been previously associated with lipid abnormalities, including elevations of total cholesterol and triglycerides [59]. Chronic use of tocilizumab in rheumatoid arthritis has also been shown to increase lipid parameters, in particular triglycerides [60].

Statins have been postulated as a possible add-on treatment for COVID-19 patients, based on their known immunomodulatory properties [61]. Statins exert pleiotropic effects on inflammation and oxidative stress and modulate the immune response at different levels, including immune cell adhesion and migration, antigen presentation, and cytokine production [62]. Observational studies have reported the effectiveness of statin treatment in some viral infections including reducing influenza-related hospitalizations and deaths [63]. As statins are low-cost, extensively tested, well-tolerated drugs in a health crisis such as the current COVID-19 pandemic, they could be an option when treatment with more expensive drugs may not be implemented. Continuation of preexisting statin therapy must be recommended.

\section{The pituitary and COVID-19}

Evidence of altered pituitary function in SARS was first reported by Leow et al. [64]. Sixty-one survivors of the SARS outbreak were evaluated after recovery: $40 \%$ had evidence of central mild hypocortisolism and 5\% also had central hypothyroidism [64]. Edema and neuronal degeneration along with SARS-CoV genome have been identified in the hypothalamus on autopsy studies [64]. In the case of COVID-19 both the hypothalamic and pituitary tissues express ACE2 and could also be viral targets [65]. Currently, we do not have any such data in COVID-19; however, considering the high frequency of neurological symptoms, one can assume that SARS-CoV-2 may affect the hypothalamus-pituitary as well, directly or via immune-mediated hypophysitis [66].

\subsection{Recommendations for people with pituitary disorders regarding COVID-19 infection}

Management of pituitary tumors without mass effects and without hormonal hypersecretion can be deferred for several months and if possible, all patients should receive medical therapy [67]. In the case of pituitary tumors (except prolactinomas) with severe visual deterioration, surgery is the treatment of choice, with previous assessment of COVID-19 status [68].

Patients with pre-existing endocrine conditions may be vulnerable to perturbations in plasma sodium in more severe cases of COVID-19. None of the published reports so far have reported a higher prevalence of dysnatremia in COVID-19 [69]. Regarding management of diabetes insipidus, since patients have limited accessibility to blood testing, the priority should be to avoid hyponatremia [70]. This can be performed delaying desmopressin to allow regular periods of free water 
clearance to prevent dilutional hyponatremia. It is also useful to measure body weight daily. In addition, patients with diabetes insipidus who develop respiratory complications of COVID-19 are at significantly increased risk of dysnatremia and should have a close monitorization [70].

\section{The thyroid and COVID-19}

Data on thyroid involvement by coronavirus are most scarce. A study conducted during the SARS outbreak in 2003 had reported that serum Triiodothyronine and thyroxine levels were lower in patients with SARS as compared to controls, both during the acute and convalescent phases. This could simply imply an underlying euthyroid sick syndrome. However, a study of the autopsy in five patients with SARS has shown marked destruction of the follicular and parafollicular thyroid cells [71] and not a reduction in thyroid follicular size associated with euthyroid sick syndrome [72]. Destruction of follicular cells may also be identified as a low triiodothyronine and thyroxine profile. Data on thyroid function or thyroid pathology are yet not available in COVID-19 [65].

Regarding Graves' disease, COVID-19 can be a precipitating factor for initiation or relapse of the disease (M. Marazuela, personal experience). Several medical societies have recommended to take special care to patients with hyperthyroidism receiving antithyroid drugs, because symptoms of the rare side effect of agranulocytosis can overlap with COVID-19. In this scenario, if symptoms of COVID-19, agranulocytosis should be ruled out immediately with a full blood count.

Diagnostic work-up of thyroid nodules as well as thyroid surgery for either benign or malignant thyroid nodules for differentiated thyroid cancers have been generally postponed during COVID-19 pandemic [73] -although individualized choices based on accurate risk profile analysis were recommended. Interestingly, 1 out of 12 patients who received radioiodine for differentiated thyroid carcinoma also showed interstitial pneumonia on single photon emission computed tomography [74].

\section{The adrenal and COVID-19}

\subsection{Adrenal insufficiency}

Life-long replacement treatment aiming to mimic physiologic plasma cortisol concentrations is not easy to be achieved in adrenal insufficiency patients. Many circumstances, either organic and/or psychological, might unbalance the physiologic cortisol requirements. COVID-19 pandemic may be a new reason for patient and physician concern.
Adrenal insufficiency may confer a potentially increased risk of acquiring COVID-19 infection, as this condition is associated to an impaired natural immunity function, with a defective action of neutrophils and natural killer-cells [75]. This may explain, in part, the slightly increased rate of infectious diseases in these patients, as well as an overall higher mortality. Although patients with adrenal insufficiency may have a greater risk of complications due to the potential for an adrenal crisis to be triggered by the infection, there is still no evidence that those patients have a more severe course of COVID-19 [76].

Regarding cortisol dynamics, autopsy studies performed on patients who died from SARS-CoV showed degeneration and necrosis of the adrenal cortical cells, pointing to a direct cytopathic effect of the virus. Hence, it is likely that cortisol dynamics may be altered in patients with SARS (and also with SARS-CoV-2) [65]. In addition, there is an interesting hypothesis that certain amino acid sequences in the SARS$\mathrm{CoV}$ are molecular mimics of the host adrenocorticotropic hormone (ACTH). This could blunt the stress-induced cortisol rise, as antibodies produced against the viral particles will inadvertently destroy the circulating ACTH [77]. However, it is not yet known whether SARS-CoV-2 might be employing this same strategy.

The increase in morbidity and mortality in adrenal insufficiency could also be accounted by an insufficient compensatory self-adjusted rise of the hydrocortisone dosage at the time of the beginning of an episode of the infection. In this regard, in the case of suspicion of COVID-19, the "sick days" rule should be established as soon as minor symptoms appear [78]. Additionally, patients are also recommended to have sufficient stock at home of steroid pills and hydrocortisone injections if social confinement is required during the COVID-19 outbreak. In addition, until there is enough information, patients with AI should observe stringent social distancing.

\subsection{Cushing's syndrome}

Patients with Cushing's disease, but particularly those under supraphysiologic doses of steroids [79] may be also at a higher risk of COVID-19 infection because of the steroids potential immunosuppressive action. This issue is important, as around $5 \%$ of the world's population is taking chronic corticosteroids and there is a high prevalence of AI among these patients [80]. In these cases, under empiric principles, it might be recommendable to follow the same rules as patients with adrenal insufficiency.

Regarding diagnosis and therapy of patients with endogenous Cushing's when extensive differential diagnostic testing is not feasible, it should be deferred. Salivary cortisol/ cortisone tests should be avoided due to the potential of viral contamination and infection of laboratory staff. Treatment of potential co-morbidities (such as hypertension and diabetes) 
should be optimized and medical treatment must be initiated. Any form of treatment can be considered to switch to a block and replace regime (metyrapone or ketoconazole plus glucocorticoid) in order to ease the monitoring [81].

\section{Calcium \& Hypoparathyroidism and COVID-19}

Several studies showed a key role of calcium in viral fusion for many enveloped viruses such as SARS-CoV, MERS-CoV and Ebolavirus. Moreover, calcium promoted their replication directly interacting with fusion peptides of these viruses [82-84]. Hypocalcemia had already shown to be common in patients with SARS (60\% of patients at hospital admission), although generally mild [85], and in patients with Ebola virus disease (62\%) [86]. A case of COVID-19 infection has been recently reported as possible precipitating cause of subclinical postsurgical hypoparathyroidism presenting with severe hypocalcemia [87]. This case suggested that hypocalcemia may occur also in COVID-19 infection. In fact, very recently we found in a retrospective single Institution study including 531 patients with COVID-19 a high prevalence of hypocalcemia (in about $80 \%$ of cases) on initial hospital evaluation. Hypocalcemic patients were more frequently elderly males with linear correlation between calcium levels and LDH and PCR levels. In multivariate analyses, hypocalcemia was an independent risk factor associated with hospitalization whereas it predicted ICU admission and mortality only in univariate analysis. [88].Therefore, all patients with postsurgical hypoparathyroidism should continue their treatment to avoid severe acute hypocalcemia, which can be life-threatening, and eventually should be adequately treated [89]. Moreover, mild hypoparathyroid patients not requiring chronic treatment should undergo careful surveillance in areas hit by outbreak of COVID-19 outbreaks, particularly if overweight/obese [90]. Finally, since hypocalcemia may have negative impact on cardiac outcomes [87], calcium evaluation, monitoring and adequate supplementation if needed in all hospitalized patients with COVID-19 infection is recommended.

\section{Androgens and COVID-19}

Evaluation of the gender-related distribution has revealed that men had a higher susceptibility to the virus infection and worse clinical outcomes and COVID-19 deaths compared with women. These gender differences were observed among all age groups of adult patients $[10,91]$.

A possible mechanism that may drive clinical outcomes is a compromised antiviral immune response to SARS-CoV-2 in men. Generally, androgens have an immune suppressive effect and women are disproportionately affected with inflammatory disease. Regarding SARS-CoV infected mice in males, gonadectomy or treatment with an antiandrogen compound did not affect the morbidity and mortality; conversely, estrogen depletion by ovariectomy or treatment with an estrogen receptor antagonist dramatically increased both morbidity and mortality suggesting a protective effect for the estrogen receptor signaling pathway [92]. In addition, in animal experiments, estrogen treatment upregulated estrogen receptor signaling, silenced the cytokine storm and lead to an improved survival rate.

SARS-CoV-2 viral entry requires two host proteins [93]: the angiotensin converting enzyme-2 (ACE2) and the transmembrane protease, serine 2 (TMPRSS2) Androgen receptor activity has been considered a requirement for the transcription of TMPRSS2 gene [94] and TMPRSS2 is the most frequently altered gene in primary prostate cancer [95]. The modulation of TMPRSS2 expression by testosterone has been postulated to contribute to male predominance of COVID-19 infection [96]. Since TMPRSS2 is expressed also at pulmonary level, the use of TMPRSS2 inhibitors, currently being used for prostate cancer, represents an appealing target for prevention or treatment for COVID-19 pneumonia [93].

Adverse outcomes of COVID-19 in men could also be associated to a higher prevalence of comorbidities, including hypertension, cardiovascular disease, and lung disease.

\section{Ongoing COVID-19 research involving endocrine targets}

\subsection{Role of ACE2 and inhibitors of the renin- angiotensin system}

The SARS-CoV binds to the zinc peptidase ACE2, a surface molecule that is localized in the endothelial cells of arteries and veins, arterial smooth muscle, respiratory tract epithelium, epithelia of the small intestine, and immune cells, to enter the host cell [97]. With SARS-CoV, it was shown that ACE2 overexpression facilitated viral entry and replication in cells [98]. SARS-CoV-2 probably targets the same spectrum of cells targeted by SARS-CoV, which in the lungs are primarily localized in pneumocytes and macrophages [93]. Acute respiratory distress syndrome (ARDS), which is the most serious complication of both SARS and COVID-19, is likely explained by this lung tropism. Moreover, extrapulmonary manifestations of COVID-19 may also be related to the systemic distribution of ACE2 in the gastrointestinal tract and the heart $[15,99]$. There is evidence that ACE2 expression increases on the cell membrane with the use of ACE inhibitors and angiotensin-receptor blockers [100]. There is a theoretical concern that by increasing ACE2 expression they could facilitate the entry of virus into the host cell and increase the chances of infection or its severity [101]. 
Unfortunately, data if ACE inhibitors or angiotensin-receptor blockers modify ACE2 levels or activity (or both) are lacking in experimental animal models or in humans [102]. SARSCoV-2 appears not only to gain initial entry through ACE2 but also to subsequently downregulate ACE2 expression in order that the enzyme is unable to exert protective effects in organs and this may be in part responsible for organ injury in Covid-19 [102]. At present, we cannot rule out that long-term intake of ACE inhibitors and/or angiotensin-receptor blockers may facilitate SARS-CoV-2 entry and virus replication. Conversely, it is yet unknown whether intake of ACE inhibitors and/or angiotensin-receptor blockers, when infected, is beneficial with regard to pulmonary outcome. Possibly, we are dealing here with a double-edged sword, depending on the phase of the disease: increased baseline ACE2 expression could potentially rise infectivity and ACE inhibitors/ angiotensin-receptor blockers use would be an addressable risk factor. Conversely, once infected, downregulation of ACE2 may be the hallmark of COVID-19 progression. Consequently, upregulation by preferentially using reninangiotensin system blockade and ACE2 replacement in the acute respiratory syndrome phase may turn out to be beneficial $[103,104]$. At present, to our knowledge, there are no peer reviewed experimental or clinical data demonstrating a specific benefit or risk of using ACE inhibitors, angiotensinreceptor blockers, or renin angiotensin aldosterone antagonists in COVID-19 patients. Moreover, abrupt withdrawal of renin angiotensin aldosterone antagonists in high-risk patients, including those who have heart failure or have had myocardial infarction, may result in clinical instability and adverse health outcomes. In this regard, the European Society of Cardiology, Council on Hypertension; American College of Cardiology, the American Heart Association and the Heart Failure Society of America and the American Society of hypertension have released policy statements strongly recommending that patients should continue treatment with their usual antihypertensive therapy because there is no clinical or empirical scientific evidence to suggest that treatment with ACE inhibitors or angiotensin receptor blockers should be discontinued because of the COVID-19 infection [103, 105].

\subsection{Use of oxytocin in COVID [106]}

Oxytocin exerts a dual effect by mobilizing the immune defenses, and by suppressing pathogenic responses due to overreactions of the innate immunity. In humans, in the early phases of infectious disease, oxytocin can limit the excessive proinflammatory and oxidative stress reactions, by decreasing interleukins levels [106]. Of particular interest to Covid-19, is the nitric oxide, which is a key signaling molecule acting as a host response modulator in viral infections. In humans, activation of the oxytocin receptor, which is expressed in the pulmonary artery, can produce a vasolidatory effect [107]. Oxytocin has been postulated as a prospective therapeutic agent for Covid-19.

\subsection{Use of melatonin in COVID 19}

Viruses induce an explosion of inflammatory cytokines and reactive oxygen species, and melatonin, a well-known antiinflammatory and anti-oxidative molecule, protects against acute respiratory distress syndrome caused by viral and other pathogens. Melatonin is effective in critical care patients by reducing vessel permeability, anxiety, sedation use, and improving sleeping quality, which might also be beneficial for COVID-19 patients. In addition, melatonin could be an adjuvant to prevent pulmonary fibrosis [108]. Notably, melatonin has a high safety profile [109]. There are no reports on the use of melatonin in COVID-19 to date [108].

\section{Compliance with ethical standards}

Conflict of interest The authors have declared that no competing financial interests exist.

\section{References}

1. Wu Z, McGoogan JM. Characteristics of and important lessons from the coronavirus disease 2019 (COVID-19) outbreak in China: summary of a report of 72314 cases from the Chinese Center for Disease Control and Prevention. JAMA. 2020;323: 1239.

2. Deng S-Q, Peng H-J. Characteristics of and public health responses to the coronavirus disease 2019 outbreak in China. J Clin Med. 2020;9:575.

3. Alves C, Casqueiro J, Casqueiro J. Infections in patients with diabetes mellitus: a review of pathogenesis. Indian J Endocrinol Metab. 2012;16:27.

4. Gupta R, Ghosh A, Singh AK, Misra A. Clinical considerations for patients with diabetes in times of COVID-19 epidemic. Diabetes Metab Syndr. 2020;14:211-2.

5. Zhang J, Dong X, Cao Y, Yuan Y, Yang Y, Yan Y, et al. Clinical characteristics of 140 patients infected with SARS-CoV-2 in Wuhan, China. Allergy. 2020;all:14238.

6. Wang D, Hu B, Hu C, Zhu F, Liu X, Zhang J, et al. Clinical Characteristics of 138 Hospitalized Patients With 2019 Novel coronavirus-infected pneumonia in Wuhan, China JAMA 2020;

7. Remuzzi A, Remuzzi G. COVID-19 and Italy: what next? Lancet. 2020;S0140673620306279.

8. Petrilli CM, Jones SA, Yang J, Rajagopalan H, O'Donnell LF, Chernyak Y, et al. Factors associated with hospitalization and critical illness among 4,103 patients with COVID-19 disease in New York City [internet]. Intensive care and critical care medicine; 2020 Apr. Available from:. http://medrxiv.org/lookup/doi/ 10.1101/2020.04.08.20057794.

9. Fadini GP, Morieri ML, Longato E, Avogaro A. Prevalence and impact of diabetes among people infected with SARS-CoV-2. J Endocrinol Investig. 2020;43:867-9.

10. Guan W, Ni Z, Hu Y, Liang W, Ou C, He J, et al. Clinical Characteristics of Coronavirus Disease 2019 in China. N Engl J Med. 2020;NEJMoa2002032. 
11. Li B, Yang J, Zhao F, Zhi L, Wang X, Liu L, et al. Prevalence and impact of cardiovascular metabolic diseases on COVID-19 in China. Clin Res Cardiol Off J Ger Card Soc. 2020;109:531-8.

12. Leung C. Risk factors for predicting mortality in elderly patients with COVID-19: a review of clinical data in China. Mech Ageing Dev. 2020;188:111255.

13. Center for Disease Control and Prevention. Interim Clinical Guidance for Management of Patients with Confirmed Coronavirus Disease (COVID-19). [Internet]. Httpswwwedcgovcoronavirus2019-Ncovhcpclinical-Guid.Manag.-Patientshtml. 2020 [cited 2020 Apr 3]. Available from: https://www.cdc.gov/coronavirus/2019-ncov/hcp/clinicalguidance-management-patients.html

14. Guan W, Liang W, Zhao Y, Liang H, Chen Z, Li Y, et al. Comorbidity and its impact on 1590 patients with COVID-19 in China: a nationwide analysis. Eur Respir J. 2020;55:2000547.

15. Puig-Domingo M, Marazuela M, Giustina A. COVID-19 and endocrine diseases. A statement from the European Society of Endocrinology. Endocrine. 2020;68:2-5.

16. Hill MA, Mantzoros C, Sowers JR. Commentary: COVID-19 in patients with diabetes. Metabolism. 2020;154217.

17. Morra ME, Van Thanh L, Kamel MG, Ghazy AA, Altibi AMA, Dat LM, et al. Clinical outcomes of current medical approaches for Middle East respiratory syndrome: a systematic review and meta-analysis. Rev Med Virol. 2018;28:e1977.

18. López-Cano C, Lecube A, García-Ramírez M, Muñoz X, Sánchez E, Seminario A, et al. Serum surfactant protein D as a biomarker for measuring lung involvement in obese patients with type 2 diabetes. J Clin Endocrinol Metab. 2017;102:4109-16.

19. Lecube A, Simó R, Pallayova M, Punjabi NM, López-Cano C, Turino C, et al. Pulmonary function and sleep breathing: two new targets for type 2 diabetes care. Endocr Rev. 2017;38:550-73.

20. Philips BJ, Meguer J-X, Redman J, Baker EH. Factors determining the appearance of glucose in upper and lower respiratory tract secretions. Intensive Care Med. 2003;29:2204-10.

21. Zhou J, Tan J. Diabetes patients with COVID-19 need better blood glucose management in Wuhan. China Metabolism. 2020;107: 154216.

22. Sardu C, D’Onofrio N, Balestrieri ML, Barbieri M, Rizzo MR, Messina V, et al. Outcomes in Patients With Hyperglycemia Affected by Covid-19: Can We Do More on Glycemic Control? Diabetes Care. 2020:dc200723.

23. Lucas Martín AM, Guanyabens E, Zavala-Arauco R, Chamorro J, Granada ML, Mauricio D, et al. Breaking therapeutic inertia in type 2 diabetes: active detection of in-patient cases allows improvement of metabolic control at midterm. Int $\mathrm{J}$ Endocrinol. 2015;2015:1-5.

24. Pérez Pérez A, Conthe Gutiérrez P, Aguilar Diosdado M, Bertomeu Martínez V, Galdos Anuncibay P, García de Casasola $\mathrm{G}$, et al. Tratamiento de la hiperglucemia en el hospital. Med Clínica. 2009;132:465-75.

25. Rayman G, Lumb A, Kennon B, Cottrell C, Nagi D, Page E, et al. New Guidance on Managing Inpatient Hyperglycaemia during the COVID-19 Pandemic. Diabet Med. 2020:dme.14327.

26. Cranston, Nicholson, Meeking, Butt, Kar, Cummings. Urgent Safety Notice: Use of SGLT2 inhibitors during the Covid-19 Crisis. R United Hosp Bath NHS Found Trust. 2020 Apr 3;

27. Li J, Wang X, Chen J, Zuo X, Zhang H, Deng A. COVID-19 infection may cause ketosis and ketoacidosis. Diabetes Obes Metab. 2020.

28. Bornstein SR, Rubino F, Khunti K, Mingrone G, Hopkins D, Birkenfeld AL, et al. Practical recommendations for the management of diabetes in patients with COVID-19. Lancet Diabetes Endocrinol. 2020;8:546-50.
29. Raj VS, Mou H, Smits SL, Dekkers DHW, Müller MA, Dijkman $\mathrm{R}$, et al. Dipeptidyl peptidase 4 is a functional receptor for the emerging human coronavirus-EMC. Nature. 2013;495:251-4.

30. Julián MT, Alonso N, Colobran R, Sánchez A, Miñarro A, PujolAutonell I, et al. CD26/DPPIV inhibition alters the expression of immune response-related genes in the thymi of NOD mice. Mol Cell Endocrinol. 2016;426:101-12.

31. Li K, Wohlford-Lenane CL, Channappanavar R, Park J-E, Earnest JT, Bair TB, et al. Mouse-adapted MERS coronavirus causes lethal lung disease in human DPP4 knockin mice. Proc Natl Acad Sci U S A. 2017;114:E3119-28.

32. Vankadari N, Wilce JA. Emerging COVID-19 coronavirus: glycan shield and structure prediction of spike glycoprotein and its interaction with human CD26. Emerg Microbes Infect. 2020;9: $601-4$.

33. Lu G, Hu Y, Wang Q, Qi J, Gao F, Li Y, et al. Molecular basis of binding between novel human coronavirus MERS-CoV and its receptor CD26. Nature. 2013;500:227-31.

34. Onder G, Rezza G, Brusaferro S. Case-Fatality Rate and Characteristics of Patients Dying in Relation to COVID-19 in Italy. JAMA [Internet]. 2020 [cited 2020 Apr 9]; Available from: https://jamanetwork.com/journals/jama/fullarticle/2763667

35. Dietz W, Santos-Burgoa C. Obesity and its Implications for COVID-19 Mortality. Obesity [Internet]. 2020 [cited 2020 Apr 9]; Available from: http://doi.wiley.com/10.1002/oby.22818

36. Qingxian C, Fengjuan C, Fang L, Xiaohui L, Tao W, Qikai W, et al. Obesity and COVID-19 Severity in a Designated Hospital in Shenzhen, China. SSRN Electron J [Internet]. 2020 [cited 2020 May 21]; Available from: https://www.ssrn.com/abstract= 3556658

37. ICNARC - Intensive Care National Audit \& Research Centre [Internet]. [cited 2020 May 21]. Available from: https://www. icnarc.org/

38. Simonnet A, Chetboun M, Poissy J, Raverdy V, Noulette J, Duhamel A, et al. High prevalence of obesity in severe acute respiratory syndrome coronavirus-2 (SARS-CoV-2) requiring invasive mechanical ventilation. Obesity [Internet]. 2020 [cited 2020 Apr 11]; Available from: http://doi.wiley.com/10.1002/ oby. 22831

39. Venkata C, Sampathkumar P, Afessa B. Hospitalized patients with 2009 H1N1 influenza infection: the Mayo Clinic experience. Mayo Clin Proc. 2010;85:798-805.

40. Klok FA, Kruip MJHA, van der Meer NJM, Arbous MS, Gommers D A. MPJ, Kant KM, et al. Incidence of thrombotic complications in critically ill ICU patients with COVID-19. Thromb Res. 2020;

41. Dhurandhar NV, Bailey D, Thomas D. Interaction of obesity and infections: interaction of obesity and infections. Obes Rev. 2015;16:1017-29.

42. Vieira-Potter VJ. Inflammation and macrophage modulation in adipose tissues: adipose tissue macrophage modulation. Cell Microbiol. 2014;16:1484-92.

43. Mraz M, Haluzik M. The role of adipose tissue immune cells in obesity and low-grade inflammation. J Endocrinol. 2014;222: R113-27.

44. Sattar N, McInnes IB, McMurray JJV. Obesity a risk factor for severe COVID-19 infection: multiple potential mechanisms. Circulation. 2020.

45. Honce R, Karlsson EA, Wohlgemuth N, Estrada LD, Meliopoulos VA, Yao J, et al. Obesity-Related Microenvironment Promotes Emergence of Virulent Influenza Virus Strains. Moscona A, editor. mBio. 2020;11:e03341-19, /mbio/11/2/mBio.0334119.atom.

46. Muscogiuri G, Pugliese G, Barrea L, Savastano S, Colao A. Comentary: obesity: the "Achilles heel" for COVID-19? Metabolism. 2020;108:154251. 
47. Jin Y-H, Cai L, Cheng Z-S, Cheng H, Deng T, Fan Y-P, et al. A rapid advice guideline for the diagnosis and treatment of 2019 novel coronavirus (2019-nCoV) infected pneumonia (standard version). Mil Med Res. 2020;7:4

48. Giustina A, Adler RA, Binkley N, Bouillon R, Ebeling PR, Lazaretti-Castro M, et al. Controversies in Vitamin D: summary statement from an international conference. J Clin Endocrinol Metab. 2019;104:234-40.

49. Bouillon R, Marcocci C, Carmeliet G, Bikle D, White JH, Dawson-Hughes B, et al. Skeletal and Extraskeletal actions of Vitamin D: current evidence and outstanding questions. Endocr Rev. 2019;40:1109-51.

50. Martineau AR, Jolliffe DA, Hooper RL, Greenberg L, Aloia JF, Bergman P, et al. Vitamin D supplementation to prevent acute respiratory tract infections: systematic review and meta-analysis of individual participant data. BMJ. 2017;356:i6583.

51. Christopher KB. Vitamin D and critical illness outcomes: Curr Opin Crit Care. 2016;22:332-8.

52. Giustina A, Formenti AM Re: preventing a covid-19 pandemic can high prevalence of severe hypovitaminosis D play a role in the high impact of Covid infection in Italy? BMJ march 202020 https://www.bmj.com/content/368/bmj.m810/rr-36

53. Sempos CT, Heijboer AC, Bikle DD, Bollerslev J, Bouillon R, Brannon PM, et al. Vitamin D assays and the definition of hypovitaminosis D: results from the first international conference on controversies in Vitamin D. Br J Clin Pharmacol. 2018;84(10): 2194-207. https://doi.org/10.1111/bcp.13652.

54. Ebeling PR, Adler RA, Jones G, Liberman UA, Mazziotti G, Minisola S, et al. MANAGEMENT OF ENDOCRINE DISEASE: therapeutics of vitamin D. Eur J Endocrinol. 2018: R239-59.

55. Giustina A, Adler RA, Binkley N, Bollerslev J, Bouillon R, Dawson-Hughes $\mathrm{B}$, et al. Consensus statement from $2^{\text {nd }}$ international conference on controversies in Vitamin D. Rev Endocr Metab Disord. 2020;21(1):89-116. https://doi.org/10.1007/ s11154-019-09532-w.

56. Mitchell F. Vitamin-D and COVID-19: do deficient risk a poorer outcome? [published online ahead of print, 2020 May 20]. Lancet Diabetes Endocrinol. 2020;S2213-8587(20)30183-2. https://doi. org/10.1016/S2213-8587(20)30183-2

57. Rubel AR, Chong PL, Abdullah MS, Asli R, Momin RN, Mani BI, et al. Letter to the Editor: Lipemic serum in patients with COVID-19 undergoing treatment. J Med Virol. 2020;jmv.25942.

58. Morrison AR, Johnson JM, Ramesh M, Bradley P, Jennings J, Smith ZR. Letter to the Editor: Acute hypertriglyceridemia in patients with COVID-19 receiving tocilizumab. J Med Virol. 2020;jmv.25907.

59. Montes ML, Pulido F, Barros C, Condes E, Rubio R, Cepeda C, et al. Lipid disorders in antiretroviral-naive patients treated with lopinavir/ritonavir-based HAART: frequency, characterization and risk factors. J Antimicrob Chemother. 2005;55:800-4.

60. Giles JT, Sattar N, Gabriel S, Ridker PM, Gay S, Warne C, et al. Cardiovascular safety of Tocilizumab versus Etanercept in rheumatoid arthritis: a randomized controlled trial. Arthritis Rheumatol Hoboken NJ. 2020;72:31-40.

61. Castiglione V, Chiriacò M, Emdin M, Taddei S, Vergaro G. Statin therapy in COVID-19 infection. Eur Heart J - Cardiovasc Pharmacother. 2020;pvaa042.

62. Zeiser R. Immune modulatory effects of statins. Immunology. 2018;154:69-75.

63. Fedson DS. Treating influenza with statins and other immunomodulatory agents. Antivir Res. 2013;99:417-35.

64. Leow MK-S, Kwek DS-K, Ng AW-K, Ong K-C, Kaw GJ-L, Lee LS-U. Hypocortisolism in survivors of severe acute respiratory syndrome (SARS). Clin Endocrinol. 2005;63:197-202.
65. Pal R, Banerjee M. COVID-19 and the endocrine system: exploring the unexplored. J Endocrinol Invest [Internet]. 2020 [cited 2020 May 21]; Available from: http://link.springer.com/10.1007/ s40618-020-01276-8

66. Chiloiro S, Capoluongo ED, Tartaglione T, Giampietro A, Bianchi A, Giustina A, et al. The changing clinical Spectrum of Hypophysitis. Trends Endocrinol Metab. 2019;30(9):590-602. https://doi.org/10.1016/j.tem.2019.06.004.

67. Melmed S, Bronstein MD, Chanson P, Klibanski A, Casanueva $\mathrm{FF}$, Wass JAH, et al. A consensus statement on acromegaly therapeutic outcomes. Nat Rev Endocrinol. 2018;14(9):552-61. https://doi.org/10.1038/s41574-018-0058-5.

68. Fleseriu M, Karavitaki N, Dekkers OM. Endocrinology in the time of COVID-19: Management of pituitary tumours. Eur J Endocrinol [Internet]. 2020 [cited 2020 May 21]; Available from: https://eje.bioscientifica.com/view/journals/eje/aop/eje-20-0473/ eje-20-0473.xml

69. Bhatraju PK, Ghassemieh BJ, Nichols M, Kim R, Jerome KR, Nalla AK, et al. Covid-19 in critically ill patients in the Seattle region - case series. N Engl J Med. 2020;382:2012-22.

70. Christ Crain M, Hoorn EJ, Sherlock M, Thompson CJ, Wass JAH. Endocrinology in the time of COVID-19: management of Hyponatraemia and diabetes Insipidus. Eur J Endocrinol. 2020;183:G9-G15.

71. Wei L, Sun S, Xu C-H, Zhang J, Xu Y, Zhu H, et al. Pathology of the thyroid in severe acute respiratory syndrome. Hum Pathol. 2007;38:95-102.

72. De Jongh FE, Jöbsis AC, Elte JW. Thyroid morphology in lethal non-thyroidal illness: a post-mortem study. Eur J Endocrinol. 2001;144:221-6.

73. Vrachimis A, Iacovou I, Giannoula E, Giovanella L. Endocrinology in the time of COVID-19: Management of thyroid nodules and cancer [published online ahead of print, 2020 May 1]. Eur J Endocrinol. 2020;EJE-20-0269.R2. https://doi. org/10.1530/EJE-20-0269

74. Albano D, Bertagna F, Bertoli M, Bosio G, Lucchini S, Motta F, et al. Incidental findings suggestive of COVID-19 in asymptomatic patients undergoing nuclear medicine procedures in a highprevalence region. J Nucl Med. 2020;61(5):632-6. https://doi.org/ 10.2967/jnumed.120.246256.

75. Bancos I, Hazeldine J, Chortis V, Hampson P, Taylor AE, Lord $\mathrm{JM}$, et al. Primary adrenal insufficiency is associated with impaired natural killer cell function: a potential link to increased mortality. Eur J Endocrinol. 2017;176:471-80.

76. Arlt W, Baldeweg SE, Pearce SHS, Simpson HL. Endocrinology in the time of COVID-19: management of adrenal insufficiency. Eur J Endocrinol. 2020.

77. Wheatland R. Molecular mimicry of ACTH in SARS - implications for corticosteroid treatment and prophylaxis. Med Hypotheses. 2004;63:855-62.

78. Arlt W. . SOCIETY FOR ENDOCRINOLOGY ENDOCRINE EMERGENCY GUIDANCE: Emergency management of acute adrenal insufficiency (adrenal crisis) in adult patients. Endocr Connect. 2016;5:G1-3.

79. Mazziotti G, Formenti AM, Frara S, Roca E, Mortini P, Berruti A, et al. MANAGEMENT OF ENDOCRINE DISEASE: risk of overtreatment in patients with adrenal insufficiency: current and emerging aspects. Eur J Endocrinol. 2017;177:R231-48.

80. Woods CP, Argese N, Chapman M, Boot C, Webster R, Dabhi V, et al. Adrenal suppression in patients taking inhaled glucocorticoids is highly prevalent and management can be guided by morning cortisol. Eur J Endocrinol. 2015;173:633-42.

81. Newell-Price J, Nieman L, Reincke M, Tabarin A. Endocrinology in the time of COVID-19: Management of Cushing's syndrome. Eur J Endocrinol [Internet]. 2020 [cited 2020 May 21]; Available 
from: https://eje.bioscientifica.com/view/journals/eje/aop/eje-200352/eje-20-0352.xml

82. Millet JK, Whittaker GR. Physiological and molecular triggers for SARS-CoV membrane fusion and entry into host cells. Virology. 2018 Apr;517:3-8.

83. Straus MR, et al. $\mathrm{Ca} 2+$ ions promote fusion of Middle East respiratory syndrome coronavirus with host cells and increase infectivity. J Virol. 2020 Apr;15.

84. Nathan L, Lai AL, Millet JK, Straus MR, Freed JH, Whittaker GR, et al. Calcium ions directly interact with the Ebola virus fusion peptide to promote structure-function changes that enhance infection. ACS Infect Dis. 2020 Feb 14;6(2):250-60.

85. Booth CM, Matukas LM, Tomlinson GA, Rachlis AR, Rose DB, Dwosh HA, et al. Clinical features and short-term outcomes of 144 patients with SARS in the greater Toronto area. JAMA. 2003;289: 2801-9.

86. Uyeki TM, Mehta AK, Davey RT, Liddell AM, Wolf T, Vetter P, et al. Clinical Management of Ebola Virus Disease in the United States and Europe. N Engl J Med. 2016;374:636-46.

87. Bossoni S, Chiesa L, Giustina A. Severe hypocalcemia in a thyroidectomized woman with Covid-19 infection. Endocrine [Internet]. 2020 [cited 2020 May 21]; Available from: http://link. springer.com/10.1007/s12020-020-02326-0

88. Di Filippo L, Formenti AM, Rovere-Querini P, Carlucci M Conte C, Ciceri F, Zangrillo A, Giustina A. Hypocalcemia is highly prevalent and predicts hospitalization in patients with COVID19 Endocrine [in press].

89. Tecilazich F, Formenti AM, Frara S, Giubbini R, Giustina A. Treatment of hypoparathyroidism. Best Pract Res Clin Endocrinol Metab. 2018;32:955-64.

90. Formenti AM, Tecilazich F, Frara S, Giubbini R, De Luca H, Giustina A. Body mass index predicts resistance to active vitamin D in patients with hypoparathyroidism. Endocrine. 2019;66:699700 .

91. Chen N, Zhou M, Dong X, Qu J, Gong F, Han Y, et al. Epidemiological and clinical characteristics of 99 cases of 2019 novel coronavirus pneumonia in Wuhan, China: a descriptive study. Lancet Lond Engl. 2020;395:507-13.

92. Channappanavar R, Fett C, Mack M, Ten Eyck PP, Meyerholz DK, Perlman S. Sex-Based Differences in Susceptibility to Severe Acute Respiratory Syndrome Coronavirus Infection. J Immunol Baltim Md 1950. 2017;198:4046-53.

93. Hoffmann M, Kleine-Weber H, Schroeder S, Krüger N, Herrler T, Erichsen S, et al. SARS-CoV-2 cell entry depends on ACE2 and TMPRSS2 and is blocked by a clinically proven protease inhibitor. Cell. 2020;181:271-280.e8.

94. Lucas JM, Heinlein C, Kim T, Hernandez SA, Malik MS, True $\mathrm{LD}$, et al. The androgen-regulated protease TMPRSS2 activates a proteolytic cascade involving components of the tumor microenvironment and promotes prostate cancer metastasis. Cancer Discov. 2014;4:1310-25.

95. Tomlins SA. Recurrent fusion of TMPRSS2 and ETS transcription factor genes in prostate Cancer. Science. 2005;310:644-8.
96. Stopsack KH, Mucci LA, Antonarakis ES, Nelson PS, Kantoff PW. TMPRSS2 and COVID-19: Serendipity or Opportunity for Intervention? Cancer Discov. 2020;candisc;2159-8290.CD-200451v3.

97. Hanff TC, Harhay MO, Brown TS, Cohen JB, Mohareb AM. Is there an association between COVID-19 mortality and the reninangiotensin system-a call for epidemiologic investigations. Clin Infect Dis Off Publ Infect Dis Soc Am. 2020.

98. Li W, Moore MJ, Vasilieva N, Sui J, Wong SK, Berne MA, et al. Angiotensin-converting enzyme 2 is a functional receptor for the SARS coronavirus. Nature. 2003;426:450-4.

99. Chen C, Zhou Y, Wang DW. SARS-CoV-2: a potential novel etiology of fulminant myocarditis. Herz. 2020;45:230-2.

100. Ferrario CM, Jessup J, Chappell MC, Averill DB, Brosnihan KB, Tallant EA, et al. Effect of angiotensin-converting enzyme inhibition and angiotensin II receptor blockers on cardiac angiotensinconverting enzyme 2. Circulation. 2005;111:2605-10.

101. Fang L, Karakiulakis G, Roth M. Are patients with hypertension and diabetes mellitus at increased risk for COVID-19 infection? Lancet Respir Med. 2020;8:e21.

102. Vaduganathan M, Vardeny O, Michel T, McMurray JJV, Pfeffer MA, Solomon SD. Renin-angiotensin-aldosterone system inhibitors in patients with Covid-19. N Engl J Med. 2020;382:1653-9.

103. Sommerstein R, Kochen MM, Messerli FH, Gräni C. Coronavirus Disease 2019 (COVID-19): Do Angiotensin-Converting Enzyme Inhibitors/Angiotensin Receptor Blockers Have a Biphasic Effect? J Am Heart Assoc [Internet]. 2020 [cited 2020 May 21];9. Available from: https://www.ahajournals.org/doi/10.1161/JAHA. 120.016509

104. Gurwitz D. Angiotensin receptor blockers as tentative SARSCoV-2 therapeutics. Drug Dev Res. 2020.

105. Bornstein SR, Dalan R, Hopkins D, Mingrone G, Boehm BO. Endocrine and metabolic link to coronavirus infection. Nat Rev Endocrinol [Internet]. 2020 [cited 2020 Apr 12]; Available from: http://www.nature.com/articles/s41574-020-0353-9

106. Soumier A, Sirigu A. Oxytocin as a potential defence against Covid-19? Med Hypotheses. 2020;140:109785.

107. Wang P, Yang H-P, Tian S, Wang L, Wang SC, Zhang F, et al. Oxytocin-secreting system: a major part of the neuroendocrine center regulating immunologic activity. J Neuroimmunol. 2015;289:152-61.

108. Shneider A, Kudriavtsev A, Vakhrusheva A. Can melatonin reduce the severity of COVID-19 pandemic? Int Rev Immunol. 2020:1-10.

109. Zhang R, Wang X, Ni L, Di X, Ma B, Niu S, et al. COVID-19: melatonin as a potential adjuvant treatment. Life Sci. $2020 ; 117583$.

Publisher's note Springer Nature remains neutral with regard to jurisdictional claims in published maps and institutional affiliations. 